\title{
Evaluasi Performansi Jaringan UMTS di Kota Semarang menggunakan Metode Drive Test
}

\author{
HASANAH PUTRI \\ Telkom University \\ hasanahputri@tass.telkomuniversity.ac.id
}

\begin{abstract}
ABSTRAK
Saat ini penggunaan telepon seluler tidak hanya untuk komunikasi suara, melainkan juga untuk komunikasi data. Kota Semarang merupakan salah satu kota besar dengan jumlah pengguna telepon seluler yang banyak. Kondisi ini membutuhkan dukungan kualitas jaringan yang optimal dan kecepatan akses yang tinggi. Pada penelitian ini dilakukan pengujian kualitas sinyal jaringan UMTS di kota tersebut. Pengukuran dilakukan dengan metode drive test menggunakan software TEMS dan Map info dalam pengolahan datanya. Ada beberapa parameter pengamatan dalam kegiatan pengukuran kualitas jaringan UMTS ini diantaranya RSCP (Receive Signal Code Power), Ec/No, Throughput dan KPI (Key Performance indicator). Setelah dilakukan pengukuran dan analisis perlu dilakukan proses simulasi optimasi yang dilakukan menggunakan software Atoll 3.2.1. Dari hasil pengukuran diperoleh nilai parameter RSCP, $E_{c} / N_{o}$, dan Throughput berturut-turut sebesar 68,45\%, 91\%, dan 52.2\%. Setelah dilakukan simulasi optimasi terjadi peningkatan nilai parameter RSCP dan $E_{C} / N_{o}$ berturutturut sebesar $97.28 \%$ dan $99.74 \%$.
\end{abstract}

Kata kunci: UMTS, Drive Test, Map Info, Atoll, KPI.

\begin{abstract}
Today the use of mobile phone is not only for voice communication but also for data communications (mobile Internet). There are a lot of mobile phone users in Semarang, so that it requires the support of a good network quality and highspeed access. In this research, it will test and measure the signal quality UMTS network. The measurement is done with drive test method by using TEMS and Map Info software. There are several parameters of observation in quality measurement of UMTS network. They are RSCP (Received Signal Code Power), $E_{c} / N_{o}$, Throughput and KPI (Key Performance Indicator). After measurement and analysis it is needed to simulate the optimization recommendations process by using Atoll 3.2.1. to the observation's parameters. From the measurement results obtained parameter values $R S C P, E_{c} / N_{0}$, and Throughput, respectively: 68.45, $91 \%$ and $52.2 \%$. After the optimization simulation the value are increase significantly to the parameter value of RSCP and $E_{c} / N_{0}$ respectively $97.28 \%$ and 99.74\%.
\end{abstract}

Keywords: UMTS, Drive Test, Map Info, Atoll, KPI. 


\section{PENDAhULUAN}

UMTS (Universal Mobile Telecommunication System) merupakan suatu teknologi seluler yang mempunyai frekuensi pembawa $5 \mathrm{MHz}$ pada uplink dan downlink dengan alokasi frekuensi untuk uplink yaitu $1945 \mathrm{MHz}$ - $1950 \mathrm{MHz}$ dan untuk downlink yaitu $2135 \mathrm{MHz}-2140 \mathrm{MHz}$ yang memungkinkan banyak user mengakses informasi dalam frekuensi dan waktu yang sama (Halonen, 2003). Pada penelitian ini studi kasus dilakukan di daerah Alun-Alun Simpang Lima Kota Semarang. Lokasi ini merupakan pusat kota yang memiliki pengunjung yang padat dan juga merupakan area dengan gedung perkantoran dan gedung-gedung yang tinggi. Daerah ini sering terjadi gangguan seperti low coverage, dan low throughput, sehingga berdampak pada banyak pengguna, diantaranya tidak bisa memperoleh layanan dengan kualitas yang baik. Metode yang digunakan pada penelitian ini adalah metode drive test yaitu mengukur dan menganalisis kualitas jaringan UMTS dengan software TEMS. Drive test merupakan metode pengukuran yang dilakukan untuk mengamati dan melakukan optimalisasi agar dihasilkan performansi jaringan yang sesuai standar (Wardana, 2011).

Layanan yang di ukur pada penelitian ini adalah layanan voice dan data. Software yang digunakan adalah TEMS Investigation 11.0.1, Map Info Professional 12.0, Atoll 3.2.1 dan Google Earth. Parameter yang diukur dan dianalisis dalam penelitian ini diantaranya RSCP (Received Signal Code Power) yaitu parameter yang menunjukkan daya terima pengukuran dari satu kode pada channel pilot yang utama yaitu $E_{c} / N_{o}$ yaitu perbandingan dalam $\mathrm{dB}$ dari Energi chip dengan daya noise total yang diukur pada pilot channel yang utama, CSSR (Call Setup Success Rate) yaitu merepresentasikan tingkat keberhasilan pembangunan panggilan telepon, CCSR (Call Completion Success) merupakan standar pengukuran kesuksesan berkomunikasi tanpa adanya drop call, HOSR (Handover Success Rate) yaitu derajat pengukuran ketika layanan berhasil diperoleh oleh user, dan Throughput yaitu parameter jaringan $3 G$ yang menunjukan kecepatan transfer maksimum dari suatu sesi transfer data upload maupun download ke suatu server.

\section{$1.1 \quad$ Jaringan UMTS}

Teknologi telekomunikasi wireless generasi ketiga (3G) yaitu Universal Mobile Telecommunication System (UMTS). (Universal Mobile Telecommunication System) UMTS merupakan suatu evolusi dari GSM, dimana interface radionya adalah WCDMA, serta mampu melayani transmisi data dengan kecepatan yang lebih tinggi, kecepatan data yang berbeda untuk aplikasi-aplikasi dengan QoS yang berbeda (Wardana, 2011).

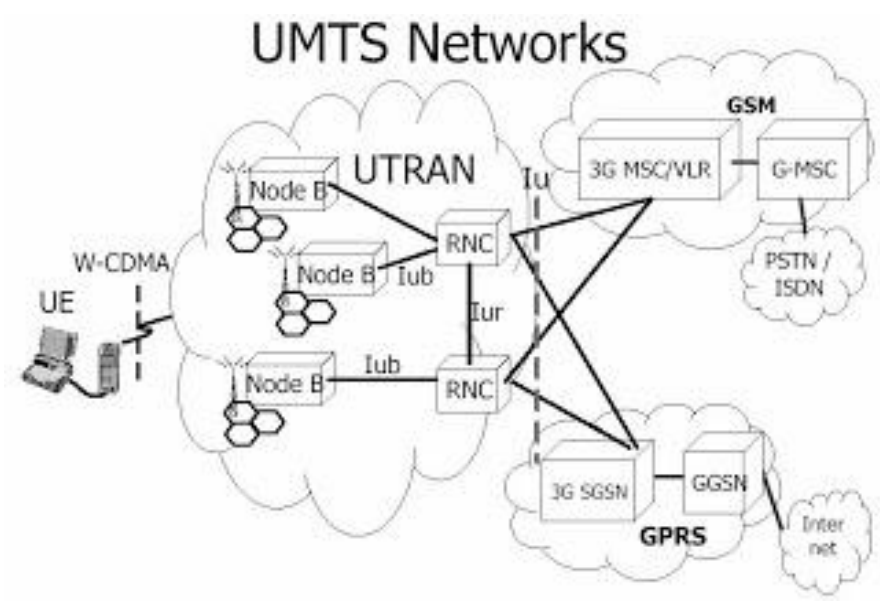

Gambar 1. Arsitektur Jaringan UMTS (Wardhana, 2011) 


\subsection{Parameter performansi jaringan UMTS (Halonen, 2003)}

Kualitas jaringan UMTS dapat dicapai dengan mengetahui performansi dari jaringan 3G tersebut, adapun beberapa parameter kualitas jaringan 3G yang diukur dari pengambilan data antara lain:

\subsubsection{Receive Signal Code Power (RSCP)}

RSCP adalah Reception Level (RxL) adalah tingkat kekuatan sinyal di jaringan 2G yang diterima ponsel, sedangkan untuk 3G (UMTS) menggunakan istilah Received Signal Code Power (RSCP). Skala RxL antara $-47 \mathrm{dBm}$ s.d. $-110 \mathrm{dBm}$ (bila menunjuk angka lebih besar dari $-85 \mathrm{dBm}$ Sangat Baik, $-92 \mathrm{dBm}$ s.d. $-85 \mathrm{dBm}$ Baik, $-105 \mathrm{dBm}$ s.d. $-92 \mathrm{dBm}$ Cukup Baik, dan $<-105 \mathrm{dBm}$ Kurang Baik). Untuk RSCP menggunakan skala $-47 \mathrm{dBm}$ s.d. $-120 \mathrm{dBm}$ (>$80 \mathrm{dBm}$ Sangat Baik, $-92 \mathrm{dBm}$ s.d. $-80 \mathrm{dBm}$ Baik, $-102 \mathrm{dBm}$ s.d. $-92 \mathrm{dBm}$ Cukup Baik, dan $<-120 \mathrm{dBm}$ Kurang Baik).

\subsubsection{Energy Carrier to Noise $\left(E_{c} / N_{o}\right)$}

Untuk memahami apa yang dimaksud dengan $E_{c} / N_{o}$ kita harus mengetahui dengan apa yang dimaksud dengan $E_{b} / N_{o}$. $E_{b} / N_{o}$ adalah perbandingan antara energi tiap bit sinyal informasi terhadap sinyal interferensi atau sinyal derau (noise) yang menyertainya, sedangkan $E_{c} / N_{o}$ adalah perbandingan antara energi setiap chip sinyal informasi terhadap sinyal interferensi atau sinyal derau (noise) yang menyertainya. Pada intinya adalah perbandingan antara kuat sinyal yang dikehendaki terhadap kuat sinyal yang tidak dikehendaki. Makin besar nilai $E_{b} / N_{o}$ atau $E_{C} / N_{o}$ maka makin memberikan performasnsi yang lebih baik Kadang-kadang kita mendapati juga istilah $E_{b} / N_{o}$ atau $E_{c} / N_{o}$, perbedaanya adalah apabila $E_{b} / N_{o}$ atau $E_{c} / N_{o}$ diukur dengan menggunakan $U E$ sedangkan $E_{b} / N_{o}$ atau $E_{c} / N_{o}$ diukur dengan menggunakan scanning device.

\subsubsection{Throughput}

Throughput adalah parameter jaringan $3 G$ yang menunjukan kecepatan transfer maksimum dari suatu sesi transfer data upload maupun download ke suatu server.

\section{$1.3 \quad$ Metode Drive Test}

Drive Test merupakan pengukuran yang dilakukan untuk mengamati dan melakukan optimalisasi agar dihasilkan kondisi ataupun kriteria dari performansi jaringan. Drive Test dapat dilakukan dengan menggunakan sebuah mobil dengan kecepatan rendah yang didalamnya telah dipasang perlengkapan untuk drive test, atau dapat dilakukan secara manual atau walk test yang biasanya dilakukan dalam sebuah bangunan atau area sekitar Node- $B$. Adapun metode pengambilan drive test adalah sebagai berikut.

\section{SSV (Single Site Verification)}

SSVmerupakan metode drive test untuk memverifikasi kondisi suatu site bagus atau tidak. SSV biasanya dilakukan pada sebuah site yang baru on-air untuk mengecek fungsionalitas seperti voice call, PS download, SHO, atau ISHO berhasil dengan baik, mengecek power yang dipancarkan sesuai dengan coverage plot dan juga mengecek adanya swap feeder atau swap antena.

\section{Drive Test Cluster}

Drive test Cluster merupakan drive test yang digunakan untuk mengukur jaringan suatu cluster atau daerah yang terdiri dari beberapa site namun hanya untuk satu operator jaringan. 


\section{Drive Test Benchmark}

Drive test Benchmark merupakan metode drive test yang digunakan untuk membandingkan beberapa operator dalam suatu cluster atau daerah.

\subsection{Optimasi}

Proses optimasi jaringan akses radio seluler adalah proses dimana semua informasi mengenai hardware konfigurasi, hardware problem, konfigurasi antena (ketinggian, azimuth, tilting), parameter setting, topologi jaringan dan informasi aktivitas yang berkaitan dengan topologi jaringan, definisi KPI (Key Performance Indicator), dan juga performansi jaringan harus dikumpulkan sebagai sebuah kesatuan informasi untuk melakukan analisis dan improvement pada sebuah jaringan seluler.

Pengaturan jaringan merupakan suatu kegiatan pengaturan elemen-elemen jaringan untuk mendapatkan peformansi yang maksimal. Ada 2 cara melakukan pengaturan jaringan yaitu non physical tuning (BSS parameter) dan physical tuning (tilting antena, antena relocation, dan sebagainya). Tilting merupakan pengarahan Sudut Tilting elevasi pada antena. Ada 2 jenis tilting pada antena yaitu mechanical downtilt (MDT) dan electrical downtilt (EDT). Tujuan dari tilting adalah agar pancaran antena mengarah pada coverage area yang seharusnya atau dominance area. Mechanical tilting adalah mengubah azimuth antenna dan tingkat kemiringan antenna secara fisik. Dampak yang dihasilkan oleh mechanical tilting adalah berubahnya luas coverage area secara keseluruhan. Electrical tilting adalah kegiatan mengubah daya pancar antenna dengan cara mengatur parameter kelistrikan pada antenna. Berbeda dengan mechanical tilting, perubahan pada electrical tilt hanya akan berdampak pada ukuran main lobe yang dipancarkan oleh antena.

\section{METODOLOGI PENELITIAN}

Pengukuran dan analisis kondisi performansi jaringan UMTS di Kota Semarang ini menggunakan metode drive test dengan menerapkan prosedur-prosedur pengukuran sesuai standar penyedia layanan seluler. Setelah dilakukan pengukuran dan ditemukan adanya masalah performansi dan parameter-parameter kinerja berada di bawah standar provider seluler makan dilakukan tindakan optimasi performansi sesuai prosedur optimasi. Optimasi kualitas jaringan UMTS pada penelitian ini menggunakan software Tems Investigation 11.0.1 untuk mengukur kualitas jaringan UMTS dan untuk hasil drive test akan diolah menggunakan software Map Info 12.0 sedangkan proses simulasi optimasi disimulasikan menggunakan software Atoll 3.2.1. Hasil simulasi optimasi ini menjadi salah satu referensi bagi operator atau provider seluler dalam melakukan optimasi kualitas jaringan UMTS di Alun-alun Simpang Lima Kota Semarang. Adapun alur penelitian ini seperti terlihat pada Gambar 2. 


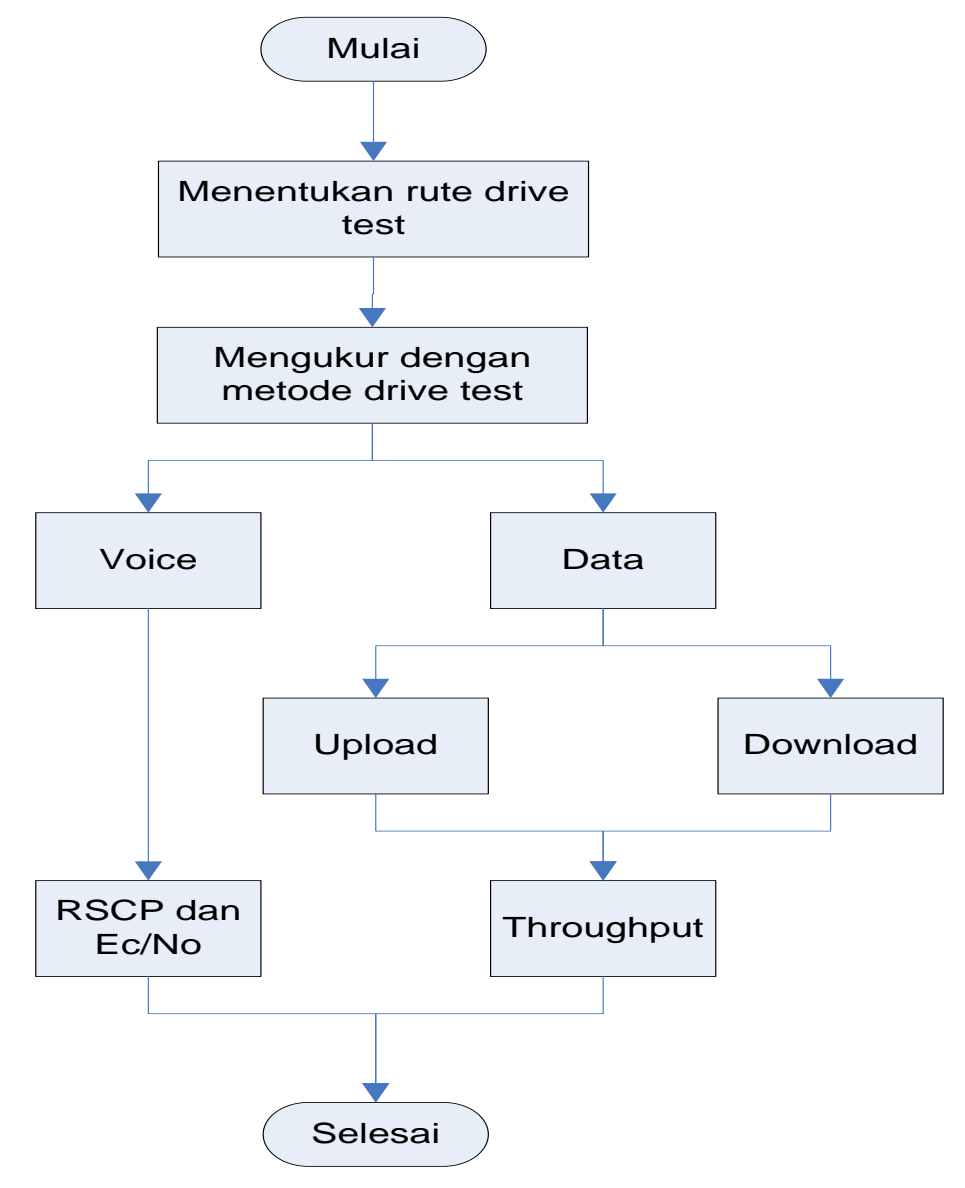

\section{Gambar 2. Alur Pengukuran Performansi Jaringan UMTS menggunakan Metode Drive Test}

Pengukuran performansi jaringan UMTS dimulai dengan menentukan rute drive test, melalui survei lokasi terlebih dahulu. Setelah ditetapkan rute drive test, dilanjutkan dengan mengukur performansi menggunakan TEMS Investigation. Adapun layanan yang diuji saat drive test yaitu layanan voice dan data.

Drive test merupakan proses pengukuran untuk melihat performansi jaringan baik pada layanan voice maupun data. Drive test dilakukan dengan menggunakan sebuah mobil dengan kecepatan rendah. Adapun peralatan yang digunakan untuk drive test adalah sebagai berikut.

a. Drive test tools meliputi handset Sony Erricson K800i, Sony Erricson W995, USB GPS, Kabel data, dan Laptop yang sudah terinstall software Tems Investigation.

b. Data site yang berisi database site berupa cellfile.

c. Data map yang berisi map lokasi yang akan digunakan sebagai rute drive test.

Pada penelitian ini menggunakan dua metode drive test. Adapun metode drive test yang digunakan adalah sebagai berikut.

a. Idle mode

Idle mode merupakan metode drive test yang digunakan untuk mengetahui kuat sinyal atau coverage dan kualitas suatu jaringan tanpa melakukan suatu panggilan. 


\section{b. Dedicated mode}

Dedicated mode merupakan metode drive test yang digunakan untuk mengetahui coverage dan kualitas suatu jaringan saat melakukan suatu panggilan.

Setelah dilakukan drive test dan survey di beberapa lokasi, serta karena faktor padatnya pengunjung maka pada penelitian ini ditetapkan rute drive test yang dipilih yaitu dari titik $\mathrm{A}$ ke titik B. Titik A berada di depan Bank Indonesia Semarang Jl. Imam Barjo sedangkan titik B berada di Jl. Imam Barjo. Selanjutnya adalah tahap mengukur kualitas jaringan UMTS. Tahap pengukuran kualitas jaringan UMTS dilakukan dengan menggunakan software TEMS Investigation 11.0.1. Pada penelitian ini pengukuran performansi jaringan UMTS pada layanan voice dan data. Pengukuran kualitas jaringan UMTS pada layanan data dibagi menjadi dua yaitu upload dan download.

Setelah dilakukan drive test, selanjutnya dilakukan analisis hasil drive test. Analisis hasil drive test dilakukan bertujuan untuk mengetahui permasalahan yang terjadi pada suatu jaringan setelah dilakukan pengukuran kualitas jaringan menggunakan metode drive test. Analisis hasil drive test dilakukan menggunakan software TEMS Investigation. Beberapa parameter yang dianalisis antara lain RSCP, KPI, dan PS Throughput. Pada tahap ini dilakukan tahap proses mengecek hasil drive test apakah terindikasi masalah atau tidak. Tahap ini dilakukan bertujuan untuk mengetahui permasalahan yang terjadi berdasarkan hasil drive test.

Setelah proses pengukuran dan analisis, selanjutnya melakukan simulasi optimasi. Tahap simulasi optimasi dilakukan bertujuan untuk memberikan sebuah referensi optimasi jaringan UMTS pada layanan voice maupun data. Pada penelitian ini permasalahan yang ada adalah audit site berupa perubahan tilting antena, reazimuth antena yang disimulasikan menggunakan software Atoll 3.2.1.

Pada tahap ini dilakukan analisis KPI (Key Perfomance Indicator) untuk mengetahui KPI sudah terpenuhi atau belum. Parameter KPI bisa diperoleh melalui report statistic yang diambil pada saat drive test (Holma, 2004).

\section{HASIL DAN PEMBAHASAN}

Hasil dari pengukuran performansi jaringan UMTS di Kota Semarang menunjukkan bahwa nilai parameter performansi berada dibawah standar KPI operator. Hal ini bisa berdampak buruk bagi para pengguna maupun bagi provider seluler. Oleh sebab itu, dilakukan analisis dan simulasi optimasi. Proses simulasi optimasi pada tahap ini dilakukan dengan menggunakan software Atoll 3.2.1. Teknik yang digunakan dalam tahap ini adalah teknik tilting antenna, dan re-azimuth antena untuk meningkatkan kualitas jaringan UMTS pada layanan voice dan data di Alun-alun Simpang Lima Kota Semarang.

Ada beberapa tahapan dalam melakukan optimasi performansi jaringan UMTS. Proses pertama yaitu melakukan perhitungan dan simulasi menggunakan software Atoll 3.2.1. Perhitungan dilakukan untuk menghitung besarnya nilai tilting antena. Adapun standar KPI yang digunakan pada penelitian ini diantaranya $R S C P, E_{c} / N_{o}$, dan Throughput. 


\subsection{Hasil Pengukuran}

Hasil pengukuran diperoleh hasil seperti terlihat pada Gambar 3. Pengukuran terhadap performansi jaringan UMTS ini dilakukan menggunakan metode drive test rute.

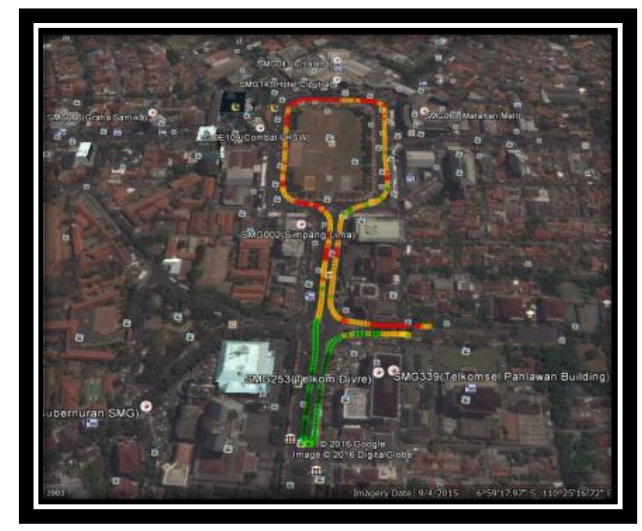

\section{Gambar 3. Hasil Pengukuran Performansi Jaringan UMTS}

Dari hasil drive test rute tersebut diperoleh data bahwa masih banyak spot atau area yang memiliki nilai performansi yang rendah. Hal ini mengindikasikan bahwa kualitas sinyal berdasarkan parameter pengamatan yaitu $R S C P, E_{c} / N_{o}$, dan Throughput, di area tersebut buruk dan dapat berdampak buruk bagi para pengguna. Sehingga perlu dilakukan optimasi untuk memperbaiki dan meningkatkan performansi jaringan UMTS di kota Semarang (Heri,2002).

Gambar 4 berikut menunjukkan Bad Coverage spot dengan nilai RSCP berada pada kisaran $104 \mathrm{dBm}$ sampai $-117 \mathrm{dBm}$.

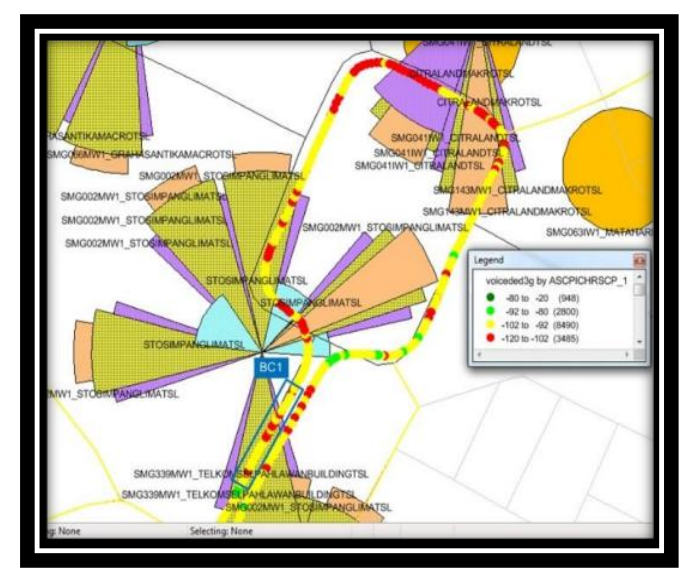

Gambar 4. Bad Coverage Spot

Pada spot ini terjadi blankspot yang disebabkan oleh serving dari site SMG002_SIMPANGLIMA sektor 2 tidak dapat menjangkau spot tersebut yang menyebabkan kondisi sinyal di spot tersebut kurang baik. 


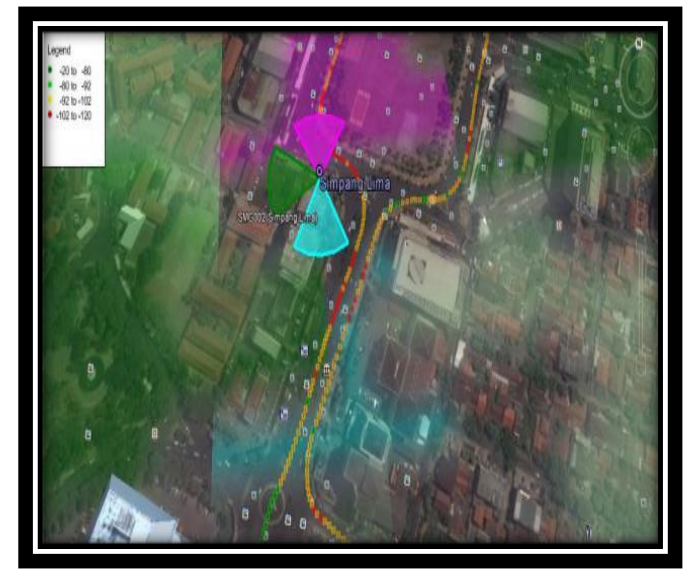

\section{Gambar 5. Pancaran site SMG002_SIMPANGLIMA}

Pada Gambar 5 di atas menunjukan pancaran site SMG002_SIMPANGLIMA sektor 2. Berdasarkan Gambar 5 di atas dapat diketahui bahwa kondisi sinyal di daerah tersebut adalah buruk. Oleh sebab itu perlu dilakukan perbaikan yaitu optimasi dengan salah satu teknik optimasi tilting antena pada site ini.

\subsection{Optimasi}

Dalam melakukan rekomendasi tilting perlu mempertimbangkan kelandaian tanah serta tinggi site. Gambar 6 menunjukan kelandaian tanah serta tinggi site di daerah pengamatan menggunakan software Google Earth.

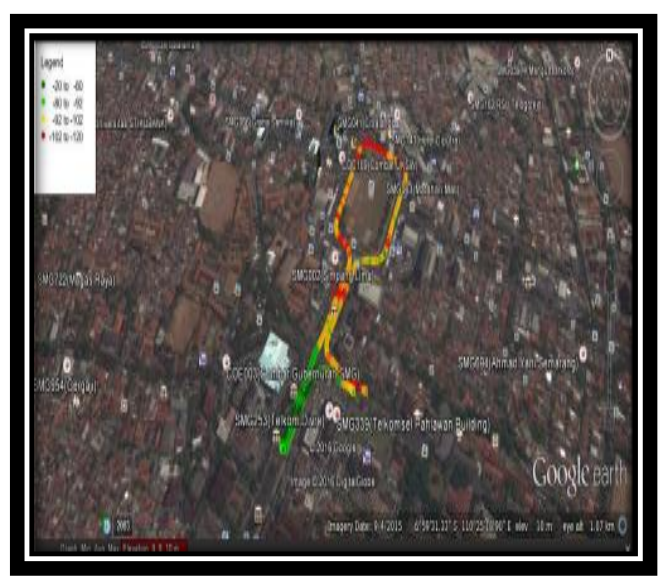

Gambar 6. Kondisi Kelandaian Tanah site SMG002_SIMPANGLIMA

Tabel 1. Data site SMG002_SIMPANGLIMA sektor 2

\begin{tabular}{|c|c|c|}
\hline No & Parameter & Nilai \\
\hline 1 & Tinggi antenna & $30.4 \mathrm{~m}$ \\
\hline 2 & Tinggi antenna + Altitude $(\mathrm{Hb})$ & $30.4 \mathrm{~m}+10 \mathrm{~m}$ \\
\hline 3 & Tinggi penerima + Altitude $(\mathrm{Hr})$ & $9 \mathrm{~m}$ \\
\hline 4 & Jarak site ke spot & $120 \mathrm{~m}$ \\
\hline 5 & Azimuth & $180^{\circ}$ \\
\hline 6 & Mechanical Tilt & $0^{\circ}$ \\
\hline 7 & Electrical Tilt & $2^{\circ}$ \\
\hline
\end{tabular}


Tabel 1 memperlihatkan data site 2 sebelum dilakukan optimasi. Nilai mechanical tilt yaitu 0。 dan electrical tilt yaitu $2^{\circ}$. Dari hasil drive test area ini perlu dilakukan optimasi. Untuk mengatasi kondisi sinyal yang kurang baik pada Bad Coverage ini maka dilakukan simulasi optimasi menggunakan software Atoll 3.2.1. Dalam melakukan tilting antena,selain menggunakan software Atoll 3.2.1 juga dapat dihitung menggunakan persamaan (1).

Sudut Tilting $=\tan ^{-1}\left(\frac{\left(h_{b}-h_{r}\right.}{\operatorname{Jarak}(m)}\right)=\tan ^{-1}\left(\frac{(40.4-9)}{120}\right)=14^{o}$

Setelah dilakukan perhitungan menggunakan persamaan (1) diperoleh sudut tilting antena yang harus diubah yaitu sebesar $14^{\circ}$. Kemudian dilakukan simulasi menggunakan tools Atoll berdasarkan hasil perhitungan tilting antena di atas maka perlu dilakukan perubahan tilting antena pada site SMG002_SIMPANGLIMA sektor 2 yaitu mechanical tilting sebesar $4^{\circ}$ dan electrical tilting sebesar $10^{\circ}$.

Tabel 2. Data site SMG002_SIMPANGLIMA sektor 2 setelah optimasi

\begin{tabular}{|c|c|c|}
\hline No & Parameter & Nilai \\
\hline 1 & Tinggi antenna & $30.4 \mathrm{~m}$ \\
\hline 2 & Tinggi antenna + Altitude $(\mathrm{Hb})$ & $30.4 \mathrm{~m}+10 \mathrm{~m}$ \\
\hline 3 & Tinggi penerima + Altitude $(\mathrm{Hr})$ & $9 \mathrm{~m}$ \\
\hline 4 & Jarak site ke spot & $120 \mathrm{~m}$ \\
\hline 5 & Azimuth & $180^{\circ}$ \\
\hline 6 & Mechanical Tilt & $4^{\circ}$ \\
\hline 7 & Electrical Tilt & $10^{\circ}$ \\
\hline
\end{tabular}

Berdasarkan hasil pengukuran nilai $R S C P$ sebelum dilakukan optimasi adalah sebesar -102 $\mathrm{dBm}$ sampai -92 dBm. Nilai ini masih dalam kategori buruk, sehingga perlu dilakukan optimasi untuk meningkatkan kualitas jaringan UMTS pada bad spot tersebut. Setelah dilakukan tilting antenna sesuai perhitungan dan simulasi, diperoleh peningkatan kualitas sinyal yaitu menjadi $-80 \mathrm{dBm}$ sampai $-20 \mathrm{dBm}$. Kualitas sinyal untuk area cakupan site SMG002_SIMPANGLIMA dapat dilihat pada Gambar 7.

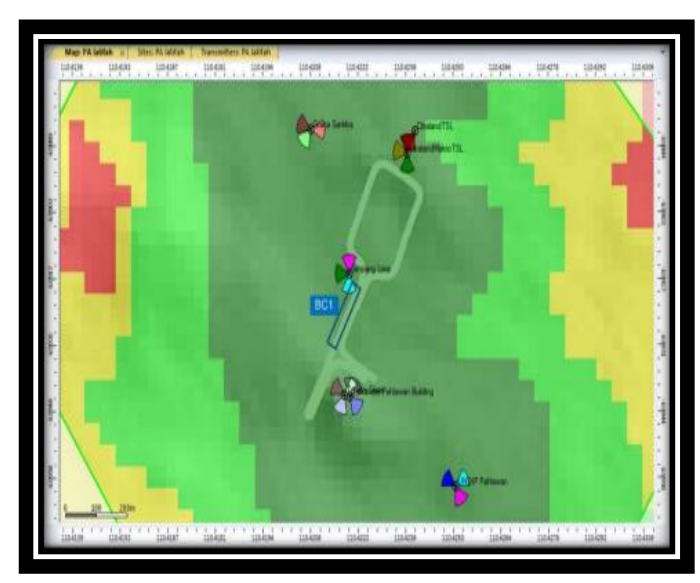

Gambar 7. Hasil Optimasi Area Cakupan Site SMG002_SIMPANGLIMA 


\subsection{Layanan Data}

Jika terdapat permasalahan dari sisi Throughput Download dan Throughput Upload maka harus dilakukan proses optimasi pada sisi coverage dan quality. Hal ini dilakukan agar dapat meningkatkan kualitas jaringan UMTS di Alun-alun Simpang Lima, Semarang. Gambar 8 berikut merupakan hasil drive test parameter Throughput.

Dapat dilihat pada Gambar 8(a) merupakan hasil drive test Throughput Download yang menunjukan bahwa nilai throughput download >64 kbps adalah sebesar 49\%, sedangkan pada Gambar 8(b) merupakan hasil drive test Throughput Upload yang menunjukan bahwa nilai throughput upload $>64 \mathrm{kbps}$ adalah sebesar 56\%. Hal tersebut menunjukan bahwa terdapat permasalahan low throughput di Alun-alun Simpang Lima Kota Semarang.

Hasil drive test digunakan sebagai dokumen analisis sebelum melakukan proses optimasi.

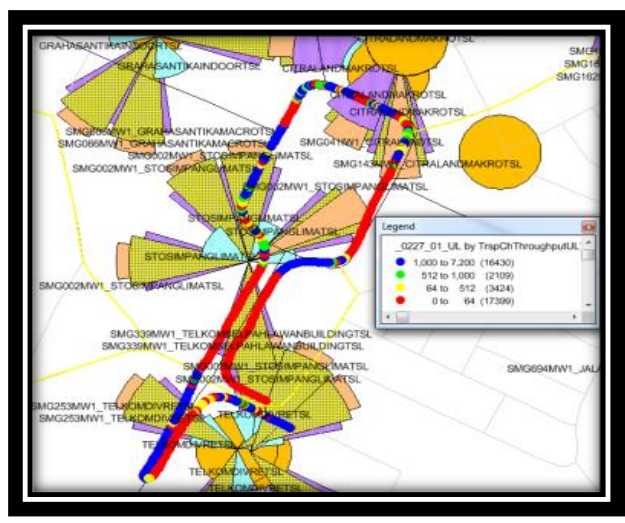

(a)

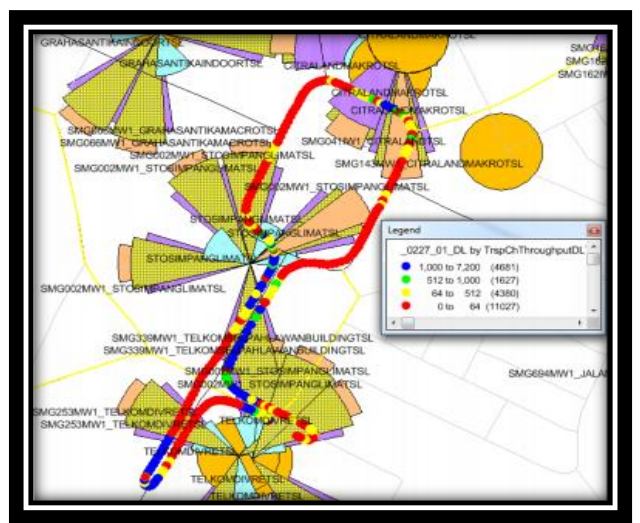

(b)

Gambar 8. (a) Hasil Drive test Throughput Download by Map Info (b) Hasil Drive test Throughput Upload by Map Info

Berdasarkan hasil drive test untuk pengamatan parameter $R S C P$ menunjukan nilai standar keberhasilan sebesar $75 \%$, sedangkan parameter $E_{c} / N_{o}$ yang menunjukkan nilai standar keberhasilan sebesar 91\%. Berdasarkan pengamatan pada sisi coverage belum memenuhi standar KPI yaitu sebesar 95\%, sedangkan pada sisi quality sudah memenuhi standar KPI yaitu sebesar $90 \%$. Permasalahan low throughput pada penelitian ini disebabkan karena buruknya coverage maupun quality yang disebabkan adanya blocking area.

Rekomendasi optimasi bagi masalah tersebut yaitu melakukan tilting antena pada site SMG002_SIMPANG LIMA sektor 2 menjadi $14^{\circ}$, yaitu mechanical tilting sebesar $4^{\circ}$ dan electrical tilting sebesar $10^{\circ}$. Rekomendasi berikutnya yaitu melakukan tilting antena pada site SMG143_CITRALAN DMAKRO sektor 2 menjadi $8^{\circ}$, yaitu mechanical tilting sebesar $3^{\circ}$ dan electrical tilting sebesar $5^{\circ}$ dan reazimuth antena sebesar $160^{\circ}$. Melakukan tilting antena pada site SMG066_GRAHASANTIKA sektor 5 menjadi $10^{\circ}$ yaitu mechanical tilting sebesar $5^{\circ}$ dan electrical tilting sebesar $5^{\circ}$ dan reazimuth antena sebesar $220^{\circ}$. Melakukan tilting antena pada site SMG002_SIMPA NGLIMA sektor 1 menjadi $6^{\circ}$ yaitu mechanical tilting sebesar $4^{\circ}$ dan electrical tilting sebesar $2^{\circ}$. Hasil optimasi menggunakan Atoll 2.3 .1 menunjukan bahwa terjadi perbaikan nilai $R S C P$ yang semula nilai standar keberhasilannya sebesar $68.45 \%$ menjadi $97.25 \%$. 
Berdasarkan hasil drive test untuk pengamatan parameter $E_{c} / N_{o}$ yang kemudian disimulasikan menunjukan bahwa nilai standar keberhasilan $E_{c} / N_{o}$ sebelum dilakukan optimasi sebesar $89.57 \%$ sehingga perlu dilakukan optimasi untuk meningkatkan kualitas jaringan UMTS pada sisi quality untuk menangani permasalahan low throughput. Setelah dilakukan simulasi optimasi diperoleh peningkatan nilai $E_{c} / N_{o}$ yang semula nilai standar keberhasilannya sebesar $89.57 \%$ menjadi $99.74 \%$. Dengan meningkatnya nilai parameter $R S C P$ dan $E_{c} / N_{o}$ ini maka meningkatkan pula parameter Throughput dari jaringan UMTS.

\section{KESIMPULAN}

Kesimpulan dari penelitian yang telah dilakukan diantaranya:

1. Hasil dari pengukuran performansi jaringan UMTS di Kota Semarang menunjukkan bahwa nilai parameter performansi jaringan UMTS berada dibawah standar KPI operator. Hal ini bisa berdampak buruk bagi para pengguna maupun bagi provider seluler terkait.

2. Teknik yang digunakan dalam tahap optimasi jaringan UMTS ini adalah teknik tilting antenna, dan re-azimuth antena.

3. Dari hasil pengukuran diperoleh nilai parameter $R S C P, E_{C} / N_{o}$, dan Throughput berturutturut sebesar $68,45 \%$ untuk nilai $R S C P, 91 \%$ untuk nilai $E_{c} / N_{o}$, dan $52.2 \%$ untuk Throughput $>64$ kbps.

4. Setelah dilakukan simulasi optimasi terjadi peningkatan nilai parameter RSCP dan $E_{c} / N_{o}$ berturut-turut sebesar $97.28 \%$ dan $99.74 \%$.

\section{DAFTAR RUJUKAN}

Wardana, L. (2011). 2G/3G RF Planning and Optimization for Consultant (plus introduction to $4 G$. Jakarta Selatan.

Halonen, T., dkk. (2003). GSM, GPRS and EDGE Performance: Evolution Toward 3G/UMTS. England.

Heri, K.. (2002). Analisis Unjuk Kerja Jaringan Operator 3G(WCDMA-UMTS) Menggunakan Metode Drivetest. Institut Teknologi Surabaya.

Holma, H. and Toskala, A. (2004). WCDMA for UMTS Radio Access For Third Generation Mobile Communication. England: John Wiley and Sons.

Huawei. WCDMA Radio Network Optimization Guide Table Of Contents. Retrived from Google.

Darlis, A. R.. (2013). Perancangan dan Implementasi Sistem Remote Tilting Antenna untuk Aplikasi Base Station. Jurnal Elkomika. 1(2) : 93-105.

Castro, J., P. (2001). The UMTS Network and Radio Access Technology-Air Interface Techniques for Future Mobile Systems. John Wiley \& Sons, Inc., Publication.

Saurabh, P., Sharma, R., Solanki, A. (2015). UMTS Networks Architecture Mobility. International Journal of Advanced Research in Computer Science and Software Engineering. 5 (7) : $1140-1144$. 